\title{
DESIGUALDADES ENTRE PACIENTES HOSPITALIZADOS POR DOENÇAS CARDIACAS E VASCULARES-CEREBRAIS EM LOCALIDADE DO ESTADO DE SÃO PAULO (BRASIL), 1986
}

\author{
Juan Stuardo Yazlle Rocha* \\ Alzira de Oliveira Jorge" \\ Breno José G. Simōes \\ Fábio Leite Vichi"
}

\begin{abstract}
YAZLLE ROCHIA, J.S. et al. Desigualdades entre pacientes hospitalizados por doenças ca rdíacas e vascularescerebrais em localidade do Estado de Såo Paulo (Brasil), 1986. Rev. Saúde públ, S. Paulo, 23: 374-81, 1989.

RESUMO: Valendo-se de um sistema de informaçðes sobre hospitalizaçðes no Município de Ribeirăo Preto, SP (Brasil) foram estudadas as características clínico-epidemiológicas referidas dos pacientes internados, em 1986, por doenças cardíacas e vasculares-cerebrais (DCVC). De 43.499 hospitalizaçöes ocorridas naquele ano, 4.673 foram ocasionadas por doenças cardiacas e vasculares-cerebrais. Utilizando a fonte de financiamento da internaçăo como indicador do estrato social ao qual pertence o paciente, foram compostos 4 grupos de estudo: particulares, "outros", previdenciários e "não pagantes"; estes grupos apresentaram diferenças significativas quanto a coeficiente de internaçoes por DCVC, média e mediana de idade na hospitalização, perfil ocupacional, duraçăo da internaçăo, freqüéncia dos sub-grupos diagnósticos, coeficientes de mortalidade e a idade média e mediana nos casos de óbitos. Estas diferenças foram atribuídas às disparidades sociais no nível de vida e condições de trabalho dos grupos estudados o que determina diferenças no adoecer, ser assistido e no morrer.
\end{abstract}

DESCRITORES: Hospitalizaçăo, tendências. Doenças cardiovasculares, epidemiologia. Classe social.

\section{INTRODUÇÃO}

Uma grande contribuição da epidemiologia social à compreensão dos problemas de saúdedoença das populações foi revelar o caráter social e histórico do fenômeno em questão. No dizer de Laurell "esta conceituaçāo nos faz compreender como cada formação social cria determinado padrão de desgaste e reprodução (dos indivíduos) ..é çlaro que o próprio padrāo social de desgaste e reprodução biológica determina o marco dentro do qual a doença é gerada". Todavia isto nāo implica numa "especificidade etiológica do social que não se expressa $\mathrm{cm}$ entidades patológicas específicas" senão em "perfis patológicos" que constituem "uma gama ampla de padecimentos específicos"s. Acrescenta Laurell: "Em termos muito gerais, o processo saúde-doença é determinado pelo modo como o homem se apropria da natureza em um dado momento, apropriaçāo que se realiza por meio de processo de trabalho baseado em determinado desenvolvimento das forças produtivas e relaçōes sociais de produção".

Esta concepção do problema permite entender que numa mesma regiāo ou país o perfil de morbi-mortalidade muda ao longo dos anos, à medida que a sociedade se transforma; que diferentes regiôes ou países tenham, num mesmo período, perfis também diferentes; ou que, numa mesma região ou país, grupos sociais diversos possuam formas diferenciadas de adoccer e morrer segundo seu padrão social de reprodução e desgaste. Vários autores, em diferentes países, têm demonstrado a desigualdade social da morbi-mortalidade e a sua vinculação ao processo de trabalho: entre outros temos: Townsend e Davidson ${ }^{17}$, Acuña ${ }^{1}$ e Ricchi ${ }^{15}$.

Temos também que nas sociedades onde domina a economia de mercado, a assistência médica é transformada em mercadoria e seu consumo se realiza segundo a posição econômica (social) dos

\footnotetext{
Departamento de Medicina Social da Faculdade de Medicina de Ribeirăo Preto da Universidade de Săo Paulo - Av.

- Bandeirantes, 3900 - 14049 - Ribeiráo Preto, SP - Brasil.

Departamento de Clínica Médica da Faculdade de Medicina de Ribeiráo Preto da Universidade de São Paulo - Av. Bandeirantes, 3900 - 14049 - Ribeirăo Preto, SP - Brasil.
} 
indivíduos. Este modelo assistencial, chamado de "medicina de classes", é atenuado toda vez que serviços sociais públicos tentam estender a cobertura de serviços de saúde, independentemente da condição social. À desigualdade social derivada das diferenças na inserção no processo produtivo tenta-se responder com a igualação no consumo, igualação esta nunca atingida nos países em desenvolvimento ${ }^{2,13}$. Disto resulta que à desigualdade social diante do processo saúde-doença agrega-se a desigualdade social no sistema de proteçāo/recuperaçāo da saúde ${ }^{22}$.

Estas considerações não podem deixar de ser levadas em conta quando estudamos a assistência médico-hospitalar, ainda quando esta satisfaz algumas condições como cobertura total da demanda através de diferentes sistemas sociais de financiamento das internaçōes. Este problema foi estudado por Forster ${ }^{4}$. A autora encontrou forte associação entre a posição social dos pacientes internados (estudando a ocupaçāo e a posiçāo social na mesma, renda e propriedades) e o sistema de financiamento da hospitalização (categoria da internação); encontrou, também, diferentes perfis de morbidade hospitalar nestes grupos sociais.

Outros estudos acerca dos perfis de morbimortalidade em populaçōes ao longo dos tempos vem confirmar o caráter social e histórico da saúde/doença mostrando a dinâmica do fenômeno com as transformações sociais. Assim é que no início do século a esperança de vida das populaçōes era aproximadamente 30 anos menor do que é a esperança de vida nos países desenvolvidos hoje; a mortalidade infantil era alta e as doenças infecto-contagiosas eram a mais importante causa de morbi-mortalidade ${ }^{6}$.

Já durante a quarta década do século, o quadro se inverte como conseqüência das transformações sociais e da melhoria nos padrões de vida. Como resultado houve o envelhecimento da população e mudança no perfil nosológico começando a destacar-se as doenças crônico-degenerativas, e entre elas as doenças cardíacas, que passam a ocupar o primeiro lugar nas causas de mortalidade geral chegando, nos Estados Unidos, a ser responsáveis por maior número de mortes por ano do que todas as outras causas associadas".

Segundo Strasser ${ }^{16}$, na atualidade, as doenças cardio-vasculares, em países desenvolvidos, representam até $75 \%$ das causas de morte de pessoas com mais de 65 anos de idade e consomem um terço das hospitalizações e mais de um quarto das consultas médicas. Quanto à morbidade, sabe- se que dentre as pessoas idosas 50 a $60 \%$ sofrem de alguma forma de doença cardiovascular. Em estudo recente sobre padrōes de mortalidade por doenças cardiovasculares em 27 países industrializados, Uemura e Pisa ${ }^{18}$ observaram, em boa parte deles, uma diminuição nas mortes por essas patologias embora continuassem a ocupar o primeiro lugar como causa de mortalidade.

Também nos países subdesenvolvidos ou em desenvolvimento, como é o caso do Brasil, as doenças crônico-degenerativas, especialmente as cardio-vasculares, vêm assumindo importância nas estatísticas de óbitos, sobretudo nos grandes centros urbanos. Lessa ${ }^{7}$, ao analisar a estrutura da mortalidade no país, em 1980 , assinalou que $24,8 \%$ dos óbitos em menores de 50 anos e mais da metade a partir daquela idade ocorreram por doenças cardio-vasculares. A mesma autora, em outro estudo ${ }^{8}$, afirma que mesmo no nordeste brasileiro, área extremamente carente, já se pode apontar mudanças no perfil da mortalidade em algumas capitais. "Assim, as taxas de mortalidade por doenças transmissíveis, em 1977, foram de 104,10 por 100 mil habitantes em Fortaleza, 219,85/ 100 mil em Recife e, 179,95/ $100 \mathrm{mil} \mathrm{em}$ Salvador. Para esses 3 municípios, somente os tumores malignos, doenças do coração e os acidentes vasculares cerebrais, juntos, foram responsáveis, na mesma ordem por 195,2 - 207,1 279,42 óbitos por 100 mil habitantes no mesmo ano". Para Laurenti ${ }^{6}$ esta é uma situação paradoxal: "por um lado as doenças não infecciosas, entre elas as cardio-vasculares, apresentam-se com freqüência alta e crescente; por outro, estão as doenças infecciosas, muitas das quais ainda em níveis bastante elevados". Essa coexistência de padrões de doenças infecto-contagiosas e crônico-degenerativas questiona o modelo social e econômico implantado no Brasil nos últimos anos.

A análise de séries históricas de mortalidade para o Brasil ${ }^{12}$ e São Paulo ${ }^{10}$ evidencia uma tendência ascendente para as doenças cardio-vasculares nas últimas décadas. Através do estudo interamericano de mortalidade urbana ${ }^{14}$ sabe-se que Ribeirāo Preto-SP encontrava-se, em fins da década de 60 , entre as cidades de maior coeficiente de mortalidade por aquelas doenças. Interessados no estudo do problema das doenças cardio-vasculares e contando no Departamento de Medicina Social (DMS) da Faculdade de Medicina de Ribeirão Preto com um Centro de Processamento de Dados Hospitalares (CPDH) ${ }^{3}$ que trabalha informaçōes acerca de todas as hospitalizações na cidade, decidiu-se desenvolver o presente estudo. 
Com o objetivo de conhecer algumas diferenças entre pacientes hospitalizados por doenças cardíacas e vasculares cerebrais (DCVC), estudamos os egressos por estas causas dos hospitais gerais de Ribcirão Preto, residentes no Município, no ano de 1986, segundo os diferentes sistemas de financiamento das internaçōes. Foram estudadas as diferenças quanto à idade, sexo, freqüência dos diagnósticos, ocupação, coeficientes de mortalidade e idade ao morrer.

\section{MATERIAL E MÉTODO}

Utilizando os recursos disponíveis no $\mathrm{CPDH}$ do DMS da Faculdade de Medicina de Ribeirão Preto da USP ${ }^{3}$, selecionamos os dados referidos de pacientes procedentes do Município de Ribeirāo Preto, com diagnóstico de doenças cardíacas e vasculares-cerebrais (DCVC) (compreendidas entre os códigos 390 a 438 da Classificação Internacional de Donças, CID, revisão de 1975). Foram incluídos no estudo os pacientes de 9 hospitais gerais da cidade, sendo um delcs um hospital universitário, regional, voltado ao atendimento de pacientes não pagantes (rotulados tradicionalmente como "indigentes"); 3 deles atendem, predominantemente, a pacientes previdenciários; um que atende preferencialmente pacientes pagantes (particulares) e os quatro restantes que atendem a previdenciários e pacientes de convênios de seguros-saúde oficiais, como o Serviço de Assistência e Seguro Social dos Municipários de Ribeirão Preto (SASSOM), o Centro Social Regional do Terceiro Batalhāo de Polícia ( $\left.3^{\circ} \mathrm{BP}\right)$, o FUNRURAL e, privados de cooperados como a UNIMED, ou empresas como a POLICLINICA-RP, e outras. De cada hospitalizaçāo foram estudados: procedência, idade, sexo, categoria da internaçāo, ocupação, diagnóstico principal (causa da internaçāo) e secundários, duraçāo da internação, e condição de saída. As fontes de financiamento da hospitalização, entendidas como as "categorias" da internaçāo, foram classificadas em: particular, INAMPS ou previdenciária, "indigentes" (os não pagantes), e "outros", incluindo aqui os pacientes de seguros-saúde privados ou públicos de certas categorias ocupacionais.

\section{RESULTADOS E DISCUSSĀO}

Em 1986, nos hospitais gerais de Ribeirão Preto, houve um total de $\mathbf{4 3 . 4 9 9}$ internaçōes de pacientes procedentes do Município, excluídos os recém-nascidos; sua distribuição segundo categorias de internação é apresentada na Tabela 1.

Como pode ser visto, mais da metade das hospitalizaçōes naquele ano ocorreu por conta da Previdência Social enquanto que as hospitalizaçōes particulares responderam por apenas 7,3\% do total das internaçōes; as restantes dividiram-se entre "indigentes" e a categoria "outros". Considerando que a população do Município era estimada em 396.375 habitantes, temos que o coeficiente geral de hospitalizações naquele ano foi de 109,6 internaçōes por mil habitantes.

Comparando estes dados com outros de anos anteriores (a este respeito ver Yazlle Rocha $^{20,21}$ ), podemos dizer que na década de 70 houve elevados coeficientes de hospitalizaçōes no Município, principalmente por conta de uma demanda induzida de internações eletivas estimulada pelo modelo médico privatista-mercantil, dominante naquele periodo, acentuadamente a meados da década de 70 , tendo variado de 121,49 a 140,91 internaçōes por mil habitantes-ano entrc 1972 e 1976. Todavia, devemos lembrar que a partir do "Plano de Reorientação de Assistência à Saúde no âmbito da Previdência Social, do Conselho Consultivo de Administração da Saúde Previdenciária (CONASP)" 11 , pela resolução da Comissāỏ Interministerial de Planejamento e Coordenação (CIPLAN) implementou-se uma política de restrição das internaçōes, vigente nos últimos anos, o que pode explicar a redução no coeficiente de internaçōes na população de Ribeirão Preto em 1986 a qual teria incidido nas condiçōes eletivas sem reprimir a demanda efetiva.

TABELA 1

Distribuição das hospitalizações de Ribeirão Preto segundo a categoria da internação*, 1986

\begin{tabular}{lcc}
\hline Categoria da Internação & Freqüuéncia & $\%$ \\
\hline Particular & 3.186 & 7,3 \\
Outros & 8.495 & 19,55 \\
INAMPS* & 23.474 & 54,02 \\
Indigente & 8.294 & 19,08 \\
Total & 43.449 & 100,00 \\
\hline
\end{tabular}

* Hospitais Gerais de Ribeirão Preto. Excluídos os recém nascidos.

** INAMPS :Instituto Nacional de Assistência Médica e Previdência Social. 
Das 43.499 internações de ribeirão-pretanos em 1986, 4.673 ocorreram por doença cardíaca ou vascular cerebral (código CID entre 390 e 438), o que resulta num coeficiente de 107,55 hospitalizaçōes por DCVC em cada mil internados. Como em 1972 este coeficiente era de $82,3^{19}$ vemos que houve aumento significativo na freqüência absoluta e relativa destas patologias em relação ao total $(+30 \%)$, apesar da redução no coeficiente de hospitalizaçōes. Considerando o número de hospitalizações por DCVC, em relação à população do município, temos que em 1972 houve 10,7 internaçōes por mil habitantes, sendo que em 1986 o coeficiente foi de 11,7 por mil habitantes, por ano (crescimento de $10 \%$ ). Este aumento relativo nas hospitalizações por doenças cardíacas e vasculares cerebrais decorre, por um lado, da política restritiva de hospitalizações apesar que esta incidiria pouco em patologias que teriam menor "elasticidade", como as DCVC e, por outro lado, por conta de um aumento real (em base populacional) tendência esta compatível com estudos que apontam para o aumento das DCVC no nosso meio ${ }^{8,10}$.

A distribuição da freqüência das hospitalizaçōes por doenças cardíacas e vasculares cerebrais segundo o sexo e a categoria da internação é apresentada na Tabela 2.

Como apresentado na Tabela 2, em 1986 ocorreram 2.191 internações $(46,9 \%)$ por DCVC do sexo masculino e $2.482(53,1 \%)$ do sexo feminino, invertendo a proporção entre os sexos observada em 1972: 52,8 e 47,2\%, respectivamente.

Mais importante do que as diferenças entre os sexos são as diferenças constatadas entre as categorias de internação. As hospitalizaçōes por DCVC não se distribuíram na mesma proporção entre as diferentes categorias das internaçöes. Destaca-se a categoria de previdenciários que apresentou 140,7 internaçōes por DCVC, em cada mil, contra 57,4 e 60,4 entre os pacientes particulares e "não-pagantes". $\mathrm{Na}$ categoria "outros" $\mathrm{O}$ coeficiente de internaçōes por DCVC foi de 80,6 em cada mil. Este diferencial de hospitalizaçōes por DCVC, entre as diversas categorias de internação, pode ser atribuído a vários fatores: à diferença de incidência de doenças cardiovasculares entre os diferentes grupos sociais que compōem cada categoria de internação; ou ao fato de que a política de assistência médica, neste caso de hospitalizaçōes por DCVC, é desigual para os diferentes grupos sociais, aqui expressos nas categorias de internação; ou ainda a ambos os fatores. A maior freqüência relativa de hospitalizaçōes por DCVC entre os previdenciários pode ser o resultado, em parte, pela maior incidência ou gravidade destas patologias entre os trabalhadores e, por outra, ao "deslocamento" de pacientes de um sistema assistencial com repressão de demanda (seja por saturação ou não acessibilidade) a outro capaz de atender às suas necessidades (pacientes indigentes e outros em direção ao sistema previdenciário). Entre os particulares, a explicação deve ser outra: não havendo repressão de demanda nesta categoria a proporção menor dos casos pode ser devida a menor incidência destas patologias neste grupo e a uma certa e pequena evasão da demanda a serviços hospitalares de grande renome, fora do município.

Quando se analisam as médias e medianas de idade na internação encontram-se diferenças entre as diversas categorias, sendo as maiores idades observadas nos pacientes particulares e a me-

TABELA 2

Distribuição das hospitalizações por DCVC de pacientes de Ribeirão Preto, segundo sexo e categoria da internação 1986

\begin{tabular}{|c|c|c|c|c|c|c|c|c|}
\hline \multirow[b]{2}{*}{$\begin{array}{l}\text { Categoria da } \\
\text { Internação }\end{array}$} & \multirow{2}{*}{\multicolumn{2}{|c|}{ Sexo }} & \multirow[b]{2}{*}{$\begin{array}{c}\text { Ambos } \\
\text { Sexos }\end{array}$} & \multirow[b]{2}{*}{$\%$} & \multicolumn{2}{|c|}{ Idade ${ }^{*}$} & \multirow{2}{*}{$\begin{array}{c}\text { Coefic. } \\
\text { Internação } \\
\text { DCVC }\end{array}$} & \multirow[b]{2}{*}{ DMI ** } \\
\hline & & & & & Média & Mediana & & \\
\hline $\begin{array}{l}\text { Particular } \\
\text { Outros } \\
\text { INAMPS *** } \\
\text { Indigente }\end{array}$ & $\begin{array}{r}86 \\
369 \\
1.485 \\
251\end{array}$ & $\begin{array}{r}.97 \\
316 \\
1.819 \\
250\end{array}$ & $\begin{array}{r}183 \\
685 \\
3.304 \\
501\end{array}$ & $\begin{array}{r}3,9 \\
14,6 \\
70,7 \\
10,0\end{array}$ & $\begin{array}{l}65,7 \\
61,8 \\
61,5 \\
49,2\end{array}$ & $\begin{array}{l}67,8 \\
62,9 \\
62,8 \\
51,3\end{array}$ & $\begin{array}{r}57,4 \\
80,6 \\
140,7 \\
60,4\end{array}$ & $\begin{array}{l}4,5 \\
5,2 \\
5,6 \\
8,2\end{array}$ \\
\hline Total & 2.191 & 2.482 & 4.673 & 100 & & & 107,5 & \\
\hline
\end{tabular}

* Excluídos 60 casos de idade ign orada.

* DMI - Duração médica de in ternação.

*** INAMPS - Instituto Nacional de Assistência Médica e Previdência Social. 
nor nos indigentes (diferença de mais de 15 anos) sugerindo que de maneira geral os trabalhadores adoecem, com maior gravidade, mais cedo do que os grupos mais privilegiados da sociedade. Outro gradiente diferencial observável é a duraçāo média da internação, menor entre os pacientes particulares e maior entre os "não-pagantes"; isto pode refletir menor disponibilidade relativa de recursos para o diagnóstico e tratamento dos mesmos, dada a saturação assistencial do hospital universitário, que implica maior gasto de tempo para elucidação diagnóstica e possível maior gravidade da doença e menor velocidade de recuperação destes pacientes.

Na Tabela 3 é apresentada a distribuição dos pacientes hospitalizados por DCVC segundo a ocupação e a categoria da internação. Vemos que as duas primeiras ocupações referidas, pelos pacientes, em ordem de freqüência, são aposentados e trabalhadores do lar e representam $76 \%$ do total. Isto se explica porque estas doenças acometem, principalmente, pessoas idosas e porque grande parte da demanda é de mulheres. As outras ocupaçōes mais destacadas são: comerciantes proprietários na categoria particular; funcionários de repartições públicas e policiais e bombeiros em "outros"; desempregados, operadores de máquinas, bombeiros e policiais e trabalhadores da construçāo, entre os previdenciários; desempre- gados, lavradores, menores e vendedores do comércio entre os "indigentes". Num estudo retrospectivo, como este, não é possível recuperar a ocupação anterior dos aposentados e nem a ocupação do chefe da família das pacientes trabalhadoras "do lar", como foi feito no estudo de Forster ${ }^{4}$. Entretanto, apesar da limitação dos dados presentes, estes são compatíveis com as conclusōes de Forster ${ }^{4}$, de que as categorias de internação dividem os pacientes em grupos sociais diferenciados, segundo a divisão social em classes.

$\mathrm{Na}$ Tabela 4 é apresentada a freqüência absoluta e relativa dos 12 grupos diagnósticos mais freqüentes referidos como a causa da hospitalização segundo as categorias de internação; somados eles constituem mais de $80 \%$ do total de internações por DCVC. A freqüência relativa foi obtida dividindo a freqüência dos casos, segundo diagnóstico e categoria da internação pelo número total de hospitalizações por DCVC na categoria correspondente, sobre o quociente da freqüência da categoria em relação ao total. Assim, no primeiro grupo diagnóstico da Tabela 4, temos 42 internaçōes na categoria particular dum total de 1.499 internaçōes por insuficiência cardíaca. A razão 42/1.499 foi dividida pelo quociente de 183/4.673 (razāo dos particulares sobre o total, ver Tabela 2) obtendo-se a freqüência relativa correspondente a 0,71 . Desta forma, se a distribuição das doenças

TABELA 3

Distribuição dos pacientes hospitalizados por DCVC segundo a ocupação e a categoria da internação. Ribeirão Preto. 1986

\begin{tabular}{|c|c|c|c|c|c|}
\hline \multirow{2}{*}{ Ocupação } & \multicolumn{4}{|c|}{ Categoria de Internaçâo } & \multirow{2}{*}{ Total } \\
\hline & Particular & Outros & INAMPS * & Indigen te & \\
\hline 14 & 48 & 271 & 1.712 & 44 & 2.075 \\
\hline 91 & 80 & 236 & 965 & 204 & 1.485 \\
\hline 13 & 2 & 8 & 82 & 53 & 145 \\
\hline 90 & 1 & 30 & 49 & 9 & 89 \\
\hline 41 & 0 & 12 & 15 & 48 & 75 \\
\hline 10 & 2 & 30 & 31 & 5 & 68 \\
\hline 89 & 1 & 5 & 52 & 8 & 66 \\
\hline 33 & 3 & 6 & 34 & 20 & 63 \\
\hline 12 & 0 & 7 & 26 & 28 & 61 \\
\hline 79 & 0 & 1 & 45 & 14 & 60 \\
\hline 30 & 15 & 7 & 36 & 1 & 59 \\
\hline 92 & 0 & 5 & 39 & 6 & 50 \\
\hline Outros & 31 & 67 & 218 & 61 & 377 \\
\hline Total & 183 & 685 & 3.304 & 501 & 4.673 \\
\hline
\end{tabular}

* INAMPS - Instituto Nacional de Assistência Médica e Previdência Social.

Código - Ocupações: 14 - Aposentados; 91 - Do lar, mordomos e cozinheiros; 13 - Desempregados; 90 - Guardas. bombeiros, policiais; 41 - Lavadores, jardineiros; 10 - Funcionários repartiçōes públicas; 89 - Operadores de máquinas; 33 - Vendedores e trabalhadores assimilados; 12 - Menores; 79 - Trabalhadores da construção; 30 - Comerctan. tes proprietários; 92 - Serven tes de bar, cantineiros. 
TABELA 4

Distribuição da frequiência absoluta e relativa dos diagnósticos de DCVC segundo as categorias de internação

\begin{tabular}{|c|c|c|c|c|c|c|c|c|c|}
\hline \multirow{2}{*}{$\begin{array}{l}\text { Código } \\
\mathrm{ClD}^{*}\end{array}$} & \multicolumn{5}{|c|}{ Categ. da Internação } & \multicolumn{4}{|c|}{ Freq. Relativa } \\
\hline & Particular & Outra & INAMPS ** & Indigente & Total & Particular & Outra & INAMPS** & Indigente \\
\hline 428 & 42 & 162 & 1.219 & 76 & 1.499 & 0,71 & 0,74 & 1,15 & 0,47 \\
\hline 401 & 21 & 126 & 321 & 36 & 504 & 1,06 & 1,70 & 0,90 & 0,66 \\
\hline 413 & 15 & 61 & 409 & 18 & 503 & 0,76 & 0,83 & 1,15 & 0,33 \\
\hline 434 & 21 & 70 & 299 & 49 & 439 & 1,22 & 1,08 & 0,96 & 1,04 \\
\hline 427 & 10 & 67 & 206 & 61 & 344 & 0,74 & 1,33 & 0,84 & 1,65 \\
\hline 410 & 18 & 32 & 159 & 31 & 240 & 1,91 & 0,91 & 0,94 & 1,20 \\
\hline 411 & 14 & 43 & 142 & 5 & 204 & 1,75 & 1,44 & 0,98 & 0,22 \\
\hline 416 & 2 & 10 & 143 & 4 & 159 & 0,32 & 0,43 & 1,27 & 0,23 \\
\hline 436 & 9 & 16 & 78 & 2 & 105 & 2,18 & 1,04 & 1,05 & 0,18 \\
\hline 431 & 4 & 10 & 33 & 25 & 72 & 1,42 & 0,95 & 0,65 & 3,24 \\
\hline 402 & 1 & 16 & 30 & 22 & 69 & 0,37 & 1,58 & 0,61 & 2,97 \\
\hline 426 & 3 & 3 & 49 & 8 & 63 & 1,21 & 0,32 & 1,10 & 1,18 \\
\hline Outros & 23 & 69 & 216 & 164 & 472 & - & - & - & - \\
\hline Total & 183 & 685 & 3.304 & 501 & 4.673 & - & - & - & - \\
\hline
\end{tabular}

* CID - Classificação In ternacional de Doenças. Os diagnósticos são apresentados em ordem decrescente de frequiência absoluta e correspondem a: 428 - Insuficiência cardíaca; 401 - Hipertensão essencial; 413 - Angina do peito; 434 - Oclusão das artérias cerebrais; 427 - Arritmias cardíacas; 410 - Infarto agudo do miocárdio; 411 - Outras formas agudas e sub-agudas da doença isquêmica do coração; 416 - Doença pulmonar crônica do coração; 436 Doença cerebrovascular aguda, mal definida; 431 - Hemorragia intracerebral; 402 - Doença cardíaca hipertensiva; 426 - Transtornos da condução.

*:* INAMPS - Institu to Nacional de Assistência Médica e Previdência Social.

nas diferentes categorias de hospitalização fosse proporcional à distribuição dos pacientes entre essas categorias, a freqüência relativa dos mesmos seria igual a um; desta forma destacamos quanto a frequiência observada se afasta, para mais ou para menos, daquela esperada na hipótese da igualdade.

Ao analisar a freqüência relativa dos diagnósticos de DCVC por categoria de internação observa-se que a distribuição destas não é proporcional à distribuição dos pacientes nas categorias. Assim, as patologias com freqüência $30 \%$ acima da esperada, na hipótese de igualdade, na categoria particular, são: 436,410 e 411 ; nos pacientes classificados dentro da categoria "outros", as patologias mais freqüentes foram: $401,402,411$ e 427; nos previdenciários as mais freqüentes foram: 416 , 428 e 413 ; nos indigentes foram as: $431,402,427 \mathrm{e}$ 410. Destacam-se, também, por ter freqüência muito menor do que a esperada, os grupos diagnósticos 411, 416 e 436 entre os pacientes não-pagantes, que certamente reflete a não priorizaçāo destes problemas na instituição acadêmica. Isto caracteriza que nas hospitalizações por DCVC não há um perfil comum de patologias entre os diferentes grupos sociais aqui estudados, que pode ser o resultado de que os diferentes sistemas assistenciais voltam-se seletivamente a diferentes problemas de saúde, segundo os interesses envolvidos em cada um. Desta forma, nâo se pode afirmar que as diferenças aqui observadas representem diferenças na incidência e prevalência destas doenças na população, posto que se trata de episódios de internação (incluindo repetiçōes).

Dos 4.673 pacientes internados por DCVC, $470(10,06 \%)$ foram a óbito e sua distribuição é apresentada na Tabela 5.

Os diagnósticos referidos, mais freqüentes, entre os pacientes que evoluíram a óbito foram: insuficiência cardíaca (428), oclusão das artérias cerebrais (434), infarto agudo do miocárdio (410), hemorragia intracerebral (431) e doença cerebrovascular aguda mal definida (436) constituindo mais de $70 \%$ dos 6́bitos por DCVC. Todavia, os coeficientes de mortalidade, por estas e outras causas de DCVC, tiveram distribuição desigual entre os diferentes grupos sociais estudados, menor entre os particulares e maior entre os "indigentes", à semelhança do padrão já descrito em outros países ${ }^{17}$, caracterizando um gradiente crescente: particulares, previdenciários, outros e "indigentes", respectivamente, sendo que nestes últimos a mortalidade hospitalar por DCVC foi $31 \%$ mais elevada que nos primeiros. Esta diferença 
TABELA 5

Distribuição dos óbitos de pacientes hospitalizados por DCVC segundo o diagnóstico principal e a categona da internação

\begin{tabular}{|c|c|c|c|c|c|c|c|c|c|c|}
\hline \multirow{3}{*}{$\begin{array}{l}\text { Diagnóstico } \\
\text { Principal }\end{array}$} & \multicolumn{8}{|c|}{ Categoria da Internação } & \multirow{2}{*}{\multicolumn{2}{|c|}{ Total }} \\
\hline & \multicolumn{2}{|c|}{ Particular } & \multicolumn{2}{|c|}{ Outros } & \multicolumn{2}{|c|}{ INAMPS * } & \multicolumn{2}{|c|}{ Indigen te } & & \\
\hline & Nọ & Coef. & No & Coef. & N! & Coef. & No & Coef. & No & Coef. \\
\hline $\begin{array}{l}401 \\
410 \\
411 \\
413 \\
427 \\
428 \\
431 \\
434 \\
436 \\
\text { Outros }\end{array}$ & $\begin{array}{l}0 \\
4 \\
1 \\
0 \\
0 \\
5 \\
3 \\
1 \\
2 \\
1\end{array}$ & $\begin{array}{r}0,0 \\
22,2 \\
7,1 \\
0 \\
0 \\
11,9 \\
75,0 \\
4,8 \\
22,2\end{array}$ & $\begin{array}{r}2 \\
4 \\
4 \\
1 \\
2 \\
14 \\
7 \\
17 \\
9 \\
14\end{array}$ & $\begin{array}{r}1,6 \\
12,5 \\
9,3 \\
1,6 \\
3,0 \\
8,6 \\
70,0 \\
24,3 \\
56,2\end{array}$ & $\begin{array}{r}8 \\
35 \\
8 \\
22 \\
10 \\
85 \\
23 \\
63 \\
30 \\
34\end{array}$ & $\begin{array}{r}2,5 \\
22,0 \\
5,6 \\
5,4 \\
4,8 \\
7,0 \\
69,7 \\
21,0 \\
38,5\end{array}$ & $\begin{array}{r}2 \\
9 \\
0 \\
1 \\
5 \\
11 \\
14 \\
8 \\
0 \\
11\end{array}$ & $\begin{array}{r}5,5 \\
29,0 \\
0 \\
5,5 \\
8,2 \\
14,5 \\
56,0 \\
16,3 \\
0\end{array}$ & $\begin{array}{r}12 \\
52 \\
13 \\
24 \\
17 \\
115 \\
47 \\
89 \\
41 \\
60\end{array}$ & $\begin{array}{r}2,4 \\
21,6 \\
6,4 \\
4,8 \\
4,9 \\
7,7 \\
65,2 \\
20,3 \\
39,0\end{array}$ \\
\hline Total & 17 & 9,29 & 74 & 10,8 & 318 & 9,62 & 61 & 12,2 & 470 & 10.1 \\
\hline $\begin{array}{l}\text { Idade Média } \\
\text { Idade Mediana }\end{array}$ & & $\begin{array}{l}70,8 \\
71,5\end{array}$ & & $\begin{array}{l}69,7 \\
73,5\end{array}$ & & $\begin{array}{l}64,2 \\
67,1\end{array}$ & & $\begin{array}{l}58,7 \\
61,3\end{array}$ & & \\
\hline
\end{tabular}

* INAMPS - Instituto Nacional de Assistência Médica e Previdência Social.

expressa a desigualdade social frente à morte, corroborando a afirmação da estreita articulação entre processo social e processo saúde-doença. Nossos dados sobre a idade média e mediana dos óbitos por DCVC nas diversas categorias de internação ilustram a grande diferença na idade de morrer dos grupos sociais, chegando a 12 anos entre as categorias particular e indigentes. A idade mediana mais avançada foi encontrada na categoria outros.

\section{CONCLUSOESS}

O estudo das hospitalizaçōes por DCVCs, segundo as categorias de internação em Ribeirão Preto, em 1986, permitiu-nos constatar, de um lado, o crescimento absoluto e relativo destas doenças nas hospitalizações em Ribeirão PretoSP; de outro, algumas desigualdades referentes a características sociais, epidemiológicas e assistenciais entre os pacientes de DCVC e relativas aos grupos populacionais aos quais pertencem, aqui estudados segundo as categorias de internação. Esta desigualdade expressou-se nos coeficientes por mil internações, nas idades médias e medianas dos pacientes na internação e nos casos de óbito, na duração média da internação, na distribuição dos grupos diagnósticos, no perfil ocupacional dos pacientes, nos coeficientes específicos de mortalidade, todos eles segundo as categorias de internação. A destacar não apenas as diferenças em si mesmas mas sobretudo o seu sentido, constante, que expressa a melhor condição dos socialmente bem aquinhoados e vice-versa.

Outra questão que se coloca a partir da perspectiva do presente estudo e dos seus resultados, é o questionamento da prática, ainda freqüente, de proceder a estudos populacionais sobre incidência ou prevalência de doenças e as açōes para a promoção/recuperação da saúde abstraindo as diferenças sociais entre os grupos envolvidos, diferenças que se expressam também na forma de adoecer, ser assistido e morrer. E freqüente associar este tipo de doenças com os "riscos", geralmente em bases individuais (hipertensão, diabetes, obesidade, hábito de fumar, e outros) aos quais é submetido o indivíduo. Com isto nāo apenas abstrai-se importantes aspectos dos problemas em estudo como também se exclui do campo de análise a vertente de maior poder explicativo. Conquistar o direito universal e igualitário à saúde significará, sobretudo, apagar as desigualdades hoje existentes. 
YAZLLE ROCHA, J.S. et al. [Inequalities among patients hospitalized for cardiac and cerebral-vascular diseases in the City of the State of S. Paulo, Brazil, 1986]. Rev. Saúde pábl, S. Paulo, 23: 374-81, 1989.

ABSTRACT: The clinical and epidemiological characteristics of hospitalizations due to cardiac and cerebral-vascular diseases (CCVD - ICD 390 - 438), which occurred in 1986, were studied on the basis of data from an information system relating to medical care in the City of Ribeiråo Preto, State of S. Paulo, Brazil. These causes accounted for 4,673 of the annual total of 43,449 hospital admissions. Using the sources of payment of the hospitalization as an indicator of the patients' social strata, the following four study groups were defined: private, social insurance, non-paying and "others". These groups showed significant differences in relation to the following variables: hospitalization rates due to CCVD, mean and median age at admission and time of death, occupation, average length of stay in the hospital, mortality rates and relative frequencies of specific sub-group diagnosis. These differences are attributed to inequalities in the standard of living and in the working conditions of the groups, which determine diverse patterns of disease, medical care and mortality.

KEYWORDS: Hospitalization, trends. Cardiovascular diseases, epidemiology. Social class.

\section{REFERENCIAS BIBLIOGRÁFICAS}

1. ACUÑA, D.L La salud desigual en Mérico. 77 ed. México, Siglo XXI Editores, 1987.

2. DONNANGELO, M.C.F. Saúde e sociedade. Săo Paulo, Livraria Duas Cidades, 1976.

3. FAVERO, M.; YAZLLE ROCHA, J.S.; HADDAD, N.; TERUEL, J.R Organizaçăo de um centro de informaçoes hospitalares em nível local. Rev. paul Hosp., 21:1517, 1973.

4. FORSTER, A.C. Hospitalizaçōes e classes sociais. Ribeirăo Preto, 1984 [Tese de Doutoramento - Faculdade de Medicina de Ribeirão Preto da USP].

5. LAURELL, A.C. A saúde-doença como processo social. In: Nunes, E.D. Medicina social: aspectos históricos e teoricos. Săo Paulo, Global Ed., 1983. p. 133-57.

6. LAURENTI, R. Epidemiologia das doenças cardiovasculares no Brasil. Arq. bras. Cardiol, 38:243-8, 1982.

7. LESSA, I. Infarto agudo no miocárdio em pacientes abaixo de 50 anos: aspectos clínicos e epidemiológicos. Arq. bras. Cardiol, 45:97-102, 1985.

8. LESSA, I.; ALMEIDA, F.A.A.; ALVES, J.F.A.; SOUZA, M.E.B.; JESUS, M. de F.S.; CARICCHIO, R. Prevaléncia de doenças crónicas em bairro de Salvador, Bahia, Brasil. BoL Ofic. sanit panamer., 93:376-87, 1982.

9. LEVY, RI. The decline in cardiovascular disease mortality. Ann. Rev. publ Hlth, 2:49-70, 1981.

10. LOLIO, C.A. de \& LAURENTI, R Mortalidade por doenças isquémicas do coraçăo no Município de Săo Paulo. Evoluçấo de 1950 a 1981 e mudanças recentes na tendéncia. Arq. bras. Cardiol, 46:153+6, 1986.

11. MINISTÉRIO DA PREVIDENCLA E ASSISTENCLA SOCLAL. Instituto Nacional de Assistencia Médica e Previdéncia Social. Plano de reorientaçäo de assisténcia d sauide no Ambito da previdencia social $2^{*} \mathrm{ed}$. Brasilia, 1982.

12. MORTALIDADE nas capitais brasileiras 1930-1980. Radis Dados, Rio de Janeiro, (7) ago. 1984.
13. POLACK, J.C. La medicina del Capital Madrid, Editorial Fundamentos, 1971.

14. PUFFER, R.R \& GRIFFITH, G.W. Caracteristicas de la mortalidad urbana. Washington, D.C., Organización Panamericana de la Salud, 1968. (OPAS-Publicación Científica, 151).

15. RICCHI, R. La muerte obrera. México, Editorial Nueva Imagem, 1981.

16. STRASSER, T. Epidemiologia de las enfermedades cardiovasculares en los ancianos. In: Strasser, T. ed. Asistencia cardiovascular de los ancianos. Ginebra, Organizacion Mundial de la Salud, 1988. p. 15-26.

17. TOWNSEND, P. \& DAVIDSON, N. Inequalities in health. Middlesex, Engl, Penguin Books, 1982.

18. UEMURA, K \& PISA, Z, Recent trends in cardiovascular disease mortality in 27 industrialized countries. Wld Hlth Statist. Quart, 38:142-62, 1985.

19. YAZLLE ROCHA, J.S. Estudo da utilização de leitos hospitalares gerais do Município de Ribeirăo Preto pela populaçăo do Município, no ano de 1972. Ribeiráo Preto, 1974. [Tese de Doutoramento - Faculdade de Medicina de Ribeirăo Preto da USP].

20. YAZLLE ROCHA, J.S. Assistencia médico-hospitalar, Ribeirăo Preto (SP), 1972-1976: consideraçð̌es para uma política de assisténcia hospitalar, Saúde Deb., S. Paulo, (6):38-41, 1978.

21. YAZLLE ROCHA, J.S. Padröes de morbidade hospitalar. consideraçóes para uma política de assistencia médicohospitalar. Rev. Saúde públ, S. Paulo, 14:58-64, 1980.

22. YAZLLE ROCHA, J.S.; ORTIZ, P.C.; FUNG, Y.T. A incidencia de cesáreas e a remuneraçăo da assisténcia ao parto. Cad. Saúde públ, Rio de Janeiro, 1:457-66, 1985.

Recebido para publicaçāo em 21/11/1988 Reqpresentado en 26/7/1989

Aprovado para publicação em 31/7/1989 